Research Article

\title{
Combined GSTM1 and GSTT1 null genotypes are strong risk factors for atherogenesis in a Serbian population
}

Ivana Grubisa ${ }^{1}$, Petar Otasevic ${ }^{2,6}$, Nada Vucinic ${ }^{1}$, Biljana Milicic ${ }^{3}$, Tanja Jozic ${ }^{4,6}$, Slobodan Krstic ${ }^{5,6}$ and Jelena Milasin

${ }^{1}$ Department of Human Genetics and Prenatal Diagnostics, Zvezdara, University Medical Center, University of Belgrade, Belgrade, Serbia.

${ }^{2}$ Dedinje Cardiovascular Institute Belgrade, Serbia.

${ }^{3}$ Department of Statistics, School of Dental Medicine, University of Belgrade, Belgrade, Serbia.

${ }^{4}$ Clinic of Cardiology, Clinical Center of Serbia, Belgrade, Serbia.

${ }^{5}$ Clinic for Emergency Surgery, Emergency Center, Clinical Center of Serbia, Belgrade, Serbia.

${ }^{6}$ Faculty of Medicine, University of Belgrade, Belgrade, Serbia

${ }^{7}$ Department of Human Genetics, School of Dental Medicine, University of Belgrade, Belgrade, Serbia.

\begin{abstract}
Oxidative stress (OS) plays an important role in atherogenesis and since glutathione S-transferases (GSTs) provide protection against OS, we have tested the hypothesis that deletion polymorphisms in two GSTS (GSTM1 and GSTT1) may affect the risk of developing atherosclerosis. A total of 382 individuals (200 patients with atherosclerosis and 182 healthy controls) were included in this association study. Genomic DNA was isolated from peripheral blood cells or from buccal epithelial cells and genotyping was performed using multiplex-PCR or real-time PCR methods. GSTM1 null genotype was significantly more frequent in atherosclerotic patients than in controls $(52.0 \%$ vs $34.1 \%)$ and individuals with the GSTM1 null genotype had an approximately 2-fold increase in atherosclerosis risk (OR: 2.1, $95 \% \mathrm{Cl}=1.39-3.17, \mathrm{P}=0.0004)$. GSTT1 null genotype alone did not show a statistically significant effect on atherosclerosis risk modulation, but the association approached significance (OR: $1.57,95 \% \mathrm{Cl}=0.94-2.64, P=0.08)$. The combined analysis showed that the presence of both genes had a protective effect against atherosclerosis ( $\mathrm{OR}=0.55,95 \% \mathrm{Cl}=0.37-0.83, P=0.005$ ) while double null genotypes led to a robust atherosclerosis risk increase (OR: $8.14,95 \% \mathrm{Cl}=2.41-27.51, \mathrm{P}<0.0001$ ). This study demonstrated that the GSTM1 null and combined GSTM1/GSTT1 null genotypes are susceptibility factors for development of atherosclerosis in a Serbian population.
\end{abstract}

Keywords: atherosclerosis, gene polymorphisms, glutathione S-transferases, oxidative stress.

Received: February 8, 2017; Accepted: October 23, 2017.

\section{Introduction}

Substantial data indicate that oxidative stress (OS) is involved in the development of atherosclerosis. Atherogenesis, one of the main risk factors for cardiovascular diseases (CVD), is initiated by oxidation of the low-density lipoprotein (LDL) and by impairment of oxidative stress-antioxidant balance. Conventional risk factors for CVD, including diabetes mellitus, hypercholesterolemia or dyslipidemia, hypertension and smoking, are generally related to OS. Patients with CVD commonly have at least one identifiable risk factor but many ischemic events occur in the absence of risk factors (Futterman and Lemberg, 1998).

Send correspondence to Jelena Milasin. Department of Human Genetics, School of Dental Medicine, University of Belgrade, Dr Subotica $8, \quad 11000$ Belgrade, Serbia. E-mail: jelena.milasin@stomf.bg.ac.rs
For this reason, there has been a deep interest in finding additional markers of oxidative stress, including gene polymorphisms, which might be used as predictors of disease risk.

Reactive oxygen species (ROS) produced by endothelial cells, smooth muscle cells (SMCs) and macrophages oxidize LDL in the subendothelial space, at the sites of endothelial damage, initiating events that culminate in the formation of atheroma. Some antioxidant enzymes such as superoxide dismutase and catalase directly eliminate ROS, while gluthatione S- transferases (GSTs) detoxify secondary cytotoxic metabolites of ROS. As phase II biotransformation enzymes, GSTs protect cellular macromolecules by catalyzing the conjugation of reduced glutathione (GSH) to exogenous and endogenous electrophilic compounds, which are, respectively, the results of either xenobiotic breakdown, or oxidative damage to lipids and DNA 
(Douglas, 1987; Berhane et al., 1994; Hayes and McLellan, 1999). Specific intracellular localization of the members of this GST superfamily has facilitated their categorization into three distinct groups: cytosolic, mitochondrial and microsomal GSTs. Cytosolic GSTs represent the largest family, and genes encoding these soluble isoforms are spread throughout the genome (Hayes and Strange, 2000). Polymorphisms in GST genes affect the activity of encoded enzymes and consequently have functional effects on redox regulation. A variety of polymorphisms have been described in the GSTs gene superfamily, but major attention has been focused on complete deletion polymorphism in $\mathrm{mu}$ (GSTM) and theta (GSTT) subfamilies since they abolish enzymatic activity. Polymorphic variants in the GSTM1 $(\mathrm{GSTM} 1 * 0)$ and $\operatorname{GSTT1}(\mathrm{GSTT} 1 * 0)$ genes produce either a functional proteins, i.e. non-null phenotypes (non-deletion alleles or heterozygous deletion) or result in the complete absence of enzymes, i.e. null phenotypes (homozygous deletion or null genotype) (Eaton and Bammler, 1999).

Many conditions have been associated with the deletion polymorphisms in GSTM and GSTT genes, including asthma (Lima et al., 2010), male infertility (Dordevic et al., 2010), end-stage renal disease (Suvakov et al., 2013), leukemia (Souza et al., 2008; Nasr et al., 2015) and lung cancer (Sharma et al., 2015; Yang et al., 2015), among others.

So far, controversial results have been reported about the importance of GSTM1 and GSTT1 null genotypes in atherogenesis in different human populations (Türkanoglu et al., 2010; Ramprasath et al., 2011; Nørskov et al., 2011; Santl Letonja et al., 2012; Cora et al., 2013; Yeh et al., 2013; Mir et al., 2016). This has prompted us to study the potential role of deletion polymorphisms in GSTM1 and GSTT1 in predicting the susceptibility to atherosclerosis in Serbian patients.

\section{Material and Methods}

\section{Study population}

A total of 382 individuals (200 patients and 182 controls) participated in this case-control study. All participants were of Serbian ethnicity and unrelated. Patients presented clinical manifestations of atherosclerosis and had been treated at Dedinje Cardiovascular Institute (DCI) or Zvezdara University Medical Center (ZUMC), Belgrade, Serbia, from 2010 to 2011.

Diagnosis of atherosclerosis was based on medical history including: presence of coronary heart disease (CHD), cerebrovascular diseases (CVD), peripheral arterial disease (PAD) and type 2 diabetes mellitus (T2DM). CHD in patients with previous myocardial infarction and stable angina pectoris was estimated by coronarography, whilst carotid atherosclerosis was estimated by high-resolution B-mode ultrasonography HDI, ATL 3500, or according to data related to carotid artery surgery. Cerebral ischemia was diagnosed according to symptoms including amaurosis fugax, transient ischemic attack and stroke, and PAD was diagnosed by ankle/brachial index $(<0.90)$ or according to previous data about lower extremity arterial surgery. The determination of T2DM was based on values of glycemia ( 2 readings of glycemia in 2 consecutive days): fasting plasma glucose concentration $\geq 7.0 \mathrm{mmol} / \mathrm{L}(126$ $\mathrm{mg} / \mathrm{dL}$ ) or glycemia in any random blood sample (regardless of meals $) \geq 11.1 \mathrm{mmol} / \mathrm{L}(200 \mathrm{mg} / \mathrm{dL})$ with the presence of typical diabetes symptoms (polyuria, polydipsia, weight loss) or based on the value of glycemia during an oral glucose tolerance test (OGTT): plasma glucose concentration during an OGTT in the $120^{\text {th }}$ minute $\geq 11.1$ $\mathrm{mmol} / \mathrm{L}(200 \mathrm{mg} / \mathrm{dL})$. Blood pressure measurements were done according to recommendation of the Seventh Report of the Joint National Committee on Prevention, Detection, Evaluation, and Treatment of High Blood Pressure (JNC7) (Chobanian et al., 2003): participants were considered hypertensive if their average (the mean of at least two measurements) systolic blood pressure (SBP) was $140 \mathrm{mmHg}$ or higher and/or their average (the mean of at least two measurements) diastolic blood pressure (DBP) was 90 $\mathrm{mmHg}$ or higher (and/or the person used antihypertensive medications). Hyperlipidemia was diagnosed if a person's complete lipid profile had total cholesterol level $\geq 6.20$ $\mathrm{mmol} / \mathrm{L}$, triglyceride level $\geq 2.3 \mathrm{mmol} / \mathrm{L}$, low density lipoprotein level $\geq 4.90 \mathrm{mmol} / \mathrm{L}$ and high density lipoprotein values $\leq 1.00 \mathrm{mmol} / \mathrm{L}$ or if a person used lipid-lowering medications. Participants were classified as smokers if they were former or current smokers, irrespective of the number of cigarettes smoked daily. Overweight or obesity was defined as body mass index $(\mathrm{BMI}) \geq 25 \mathrm{~kg} / \mathrm{m}^{2}$. Exclusion criteria were malignancy and any chronic inflammatory disease.

The control group was composed of 182 individuals who showed no evidence of CHD, CVD, PAD, T2DM, hypertension, malignancy and chronic inflammatory diseases based on laboratory and clinical checkup at ZUMC's clinics. The percentage of female $v s$. male participants in the control group corresponded to the percentage in the case group. Similarly, the age range and mean were approximately the same in the two groups.

All procedures were done in accordance with Helsinki Declaration of 1975 and the study protocol was approved by the ethical Committee of Zvezdara University Medical Center. All study participants signed the informed consent.

\section{Genetic analysis}

Genomic DNA was isolated from peripheral blood or from buccal swabs by DNeasy Blood \& Tissue Kit (Qiagen) according to the manufacturer's recommendations. Isolated DNA was stored at $4{ }^{\circ} \mathrm{C}$ until further analysis. 
For simultaneous detection of GSTM1 and GSTT1 genotypes a multiplex polymerase chain reaction (multiplex PCR) and real-time PCR were performed with primers described by Voso and coworkers (Voso et al., 2002). As an internal amplification control, primers for $\beta$-globin gene were used to exclude false negative results.

PCR mixture for multiplex PCR (total volume $50 \mu \mathrm{L}$ ) contained 2X Multiplex PCR Master Mix (2X-concentrated solution containing HotStart Taq DNA polymerase, reaction buffer, $\mathrm{MgCl}_{2}$ and dNTP (Qiagen), $0.5 \mu \mathrm{M}$ of each primer (Metabion) and $0.2 \mu \mathrm{g}$ of genomic DNA. Amplification products from this reaction were separated on 3\% agarose gels, stained with ethidium bromide $(0.5 \mu / \mathrm{mL})$ and visualized under UV light for determination of genotypes. Subjects with GSTM1 and GSTT1 null genotypes did not show amplification of fragments corresponding to 215 bp and $480 \mathrm{bp}$, respectively. An amplified $\beta$-globin gene fragment (110 bp) was observed in every PCR reaction as an indicator of a successful reaction.

Instead of randomly re-genotyping $10 \%$ of samples by the same multiplex PCR procedure to confirm the genotypes, 50 samples were additionally genotyped by real-time PCR and melting curve analysis. No discrepancies between genotypes determined in duplicate were found. Reaction mixes for real-time PCR were prepared according to the manufacturer's recommendations (for a total volume of 25 $\mu \mathrm{L})$ : 2X Maxim SYBR Green/ROX qPCR Master Mix (Fermentas Life Sciences), $0.35 \mu \mathrm{M}$ of each primer (Metabion), $<500 \mathrm{ng}$ template DNA and nuclease-free water to complete $25 \mu 1$.

\section{Statistical analysis}

Chi-square $\left(\mathrm{X}^{2}\right)$ and Student's $t$-test were used to compare demographics and clinical characteristics between case and control groups. Allele and genotype frequencies were estimated by allele counting method. Possible differences in allele and genotype frequencies between cases and controls were determined by Pearson's $\mathrm{X}^{2}$ test and Fisher's exact probability test. The risk of disease of examined genetic polymorphisms was assessed by calculating odds ratios (OR) and their $95 \%$ confidence intervals (CI). A $P$ value $<0.05$ was considered significant. Statistical analysis was carried out using SPSS software (version 17.0). Enrollment of 200 atherosclerotic patients and 182 healthy controls achieved a $97.2 \%$ power to detect a significant difference in development of atherosclerosis between the observed groups, at a two-tailed significance level of 0.05 using chi square test. Also, this sample size achieved a $99.3 \%$ power when we observed the frequency of GSTM1 and GSTT1 double null genotypes.

\section{Results}

The demographic and clinical characteristics of the studied groups are shown in Table 1. There was no signifi-
Table 1 - Demographic and clinical characteristic of atherosclerosis patients and controls.

\begin{tabular}{lccc}
\hline Variables & $\begin{array}{c}\text { Patients } \\
(\mathrm{N}=200)\end{array}$ & $\begin{array}{c}\text { Controls } \\
(\mathrm{N}=182)\end{array}$ & $P$ \\
\hline Age (years) & $60.3 \pm 6.3$ & $59.5 \pm 3.4$ & $0.12^{\mathrm{a}}$ \\
Gender, M/F N (\%) & $\begin{array}{c}131 / 69 \\
(65.5 / 34.5)\end{array}$ & $\begin{array}{c}118 / 64 \\
(64.8 / 35.3)\end{array}$ & $0.89^{\mathrm{b}}$ \\
$\begin{array}{l}\text { Overweight or obese N } \\
(\%)\end{array}$ & $112(56.0)$ & $91(50.0)$ & $0.2^{\mathrm{b}}$ \\
$\begin{array}{l}\text { Diabetes Mellitus Type } \\
\text { 2 N (\%) }\end{array}$ & $140(70.0)$ & - & $<\mathbf{0 . 0 0 0 1}^{\mathrm{b}}$ \\
$\begin{array}{l}\text { Hypertension N (\%) } \\
\text { Hyperlipidemia N (\%) }\end{array}$ & $178(89.0)$ & - & $<\mathbf{0 . 0 0 0 1}^{\mathrm{b}}$ \\
$\begin{array}{l}\text { Smoker (current or for- } \\
\text { mer) N (\%) }\end{array}$ & $98(49.0)$ & $78(42.8)$ & $0.27^{\mathrm{b}}$ \\
\hline
\end{tabular}

Data for age are presented as mean $\pm \mathrm{SD}, \mathrm{N}$ : number of subjects; $P$ : probability; ${ }^{\text {a }}$ Student's $t$-test; ${ }^{b} \mathrm{X}^{2}$ test

cant difference between cases and controls in terms of age, sex, obesity, hyperlipidemia and smoking. In contrast, there were significantly more subjects with T2DM and hypertension among patients with atherosclerosis than among controls $(P<0.0001$ for both variables).

A significant difference in GSTM1 null genotype (phenotype) frequencies between cases and control patients was observed (52.0 versus $34.1 \%$ ). No association was found between GSTT1 null genotype (phenotype) and disease but the risk approached significance $(P=0.08)$ (Table 2). GSTM1/GSTT1 combined phenotype frequencies were significantly different between cases and controls for GSTM1 non-null/GSTT non-null and GSTM null/GSTT null. The presence of both genes had a protective effect $(\mathrm{OR}=0.55,95 \% \mathrm{CI}=0.37-0.83, P=0.005)$ whilst individuals with double null genotypes had an approximate 8 -fold increase of the risk for atherogenesis $(\mathrm{OR}=8.14,95 \%$ $\mathrm{CI}=2.41-27.51, P<0.0001)($ Table 3$)$.

\section{Discussion}

It is well established that genetic factors play an important role in the pathogenesis of atherosclerosis and that genetically susceptible individuals are likely to develop the disease when exposed to endogenous and environmental risk factors, among others.

OS is the result of overproduction of reactive oxygen species and/or deficiency of antioxidant mechanisms and depends on the balance between generation of ROS and enzymatic or non-enzymatic systems of antioxidative protection. Several factors, such as hypercholesterolemia, hypertension, diabetes, obesity and aging are established risk factors for atherosclerosis-based cardiovascular diseases where OS is increased and antioxidant defenses are compromised.

GSTs, as antioxidant enzymes, represent the second line of defense, which neutralizes lipid peroxidation prod- 
Table 2 - GSTM1 and GSTT1 phenotype frequencies in patient and control groups.

\begin{tabular}{|c|c|c|c|c|c|}
\hline Phenotypes & Patients/(200) N (\%) & Controls (182) N (\%) & OR & $95 \% \mathrm{CI}$ & $P$ \\
\hline \multicolumn{6}{|l|}{ GSTM1 } \\
\hline non-null $(+/+,+/-)$ & $96(48)$ & $120(65.9)$ & & & \\
\hline null (-/-) & $104(52)$ & $62(34.1)$ & 2.1 & $1.39-3.17$ & 0.0004 \\
\hline \multicolumn{6}{|l|}{ GSTT1 } \\
\hline non-null $(+/+,+/-)$ & $154(77)$ & $153(84.1)$ & & & \\
\hline null (-/-) & $46(23)$ & $29(15.9)$ & 1.57 & $0.94-2.64$ & 0.08 \\
\hline
\end{tabular}

$\mathrm{N}$ : number of subjects; OR: odds ratio; $95 \% \mathrm{CI}$ : $95 \%$ confidence interval; $P$ : probability

Table 3 - Odds ratio analysis of combined GSTM1/GSTT1 phenotypes in patients and controls.

\begin{tabular}{lccccc}
\hline GSTM1/GSTT1 phenotypes & Patients (200) N (\%) & Controls $(182)$ N (\%) & OR & $95 \%$ CI & P \\
\hline Non-null/Non-null & $74(37)$ & $94(51.7)$ & 0.55 & $0.37-0.83$ & $\mathbf{0 . 0 0 5}$ \\
Non-null/Null & $22(11)$ & $26(14.3)$ & 0.74 & $0.40-1.36$ & 0.417 \\
Null/Non-null & $80(40)$ & $59(32.4)$ & 1.39 & $0.91-2.12$ & 0.152 \\
Null/Null & $24(12)$ & $3(1.6)$ & 8.14 & $2.41-27.51$ & $\mathbf{0 . 0 0 0 1}$ \\
\hline
\end{tabular}

N: Number of subjects; OR: odds ratio; 95\%CI: 95\% confidence interval; $P$ : probability

ucts (Sharma et al., 2006). Given the high global prevalence of CVDs, the number of studies dealing with the effects of GST polymorphisms on atherosclerosis are actually quite limited. Not only are the studies insufficient in number, but also the results are diverse and sometimes contradictory, which is in part the consequence of ethnic and geographical specificities of the studied populations.

A recent analysis of functional genetic differences in GST enzymes among six human groups with different ethnic background has shown that ethnicity strongly affects the genetic variability of GST enzymes. These data emphasize that human populations have different structure of detoxification genes, suggesting that ethnic differences influence disease risk or response to drugs (Hiragi et al., 2011; Polimanti et al., 2013).

In four large studies and meta-analyses in Danes, copy number variation (CNV) in GSTM1 and GSTT1 was not associated with risk of any ischemic vascular event or with markers of inflammation (Nørskov et al., 2011). A meta-analysis performed by Wang et al. (2010) suggested that the GSTM1 null genotype may slightly increase the risk of coronary heart disease and that interaction between unfavorable GSTs genotypes may exist.

In a Turkish population, GSTT1 and GSTM1 null genotypes, together with hypertension, were seen to play a significant role in the pathogenesis of ischemic stroke (Türkanoglu et al., 2010). It has also been reported that the GSTT1 null genotype is associated with premature morbidity and mortality in individuals with T2DM (Doney et al., 2005), and a very clear association has been shown between the GSTT1 null genotype and combined GSTM1 and GSTT1 null genotypes, and complications related to diabe- tes such as atherosclerosis (Ramprasath et al., 2011; Santl Letonja et al., 2012).

In the present study, a significant difference in GSTM1 genotype distribution was found between cases and controls and homozygous GSTM1 deletion significantly increased the risk of clinical manifestations of atherosclerosis. This risk increase was even more pronounced in individuals with the deletion of both genes.

The level of expression of GSTs is a crucial factor in determining the sensitivity of cells to a broad spectrum of toxic chemicals. GSTs are highly expressed enzymes with a complex transcriptional and posttranscriptional regulation and with structurally very different inducers, many of them being substrates at the same time. Patients with genetic variations that result in the absence or very little corresponding enzyme, show more severe clinical as well as biochemical and cellular phenotypes than patients carrying variations that still produce some residual protein amounts and enzyme activity (Olsen et al., 2013). GST induction is considered part of an adaptive response mechanism to chemical stress caused by electrophiles. Since GSTs production determines an individual's ability to detoxify products of ROS, especially endogenous products of oxidative damage, double deletions of GSTM1 and GSTT1 resulting in lower levels of GSTs are likely to play an important role in the development of diseases related to oxidative stress, including atherosclerosis.

A major contribution of a single gene is very unlikely in multifactorial diseases such as atherosclerosis, where a large number of pathogenetic mechanisms lead to a clinical outcome (Dalepiane et al., 2007). Thus effects of a loss-offunction polymorphism alone are probably not sufficient to influence the progression of atherosclerosis, but the accu- 
mulation of "unfavorable" oxidative stress-associated gene polymorphisms is likely associated with the evolution of its clinical manifestations (Katakami et al., 2009).

From the present study, it seems that GSTM1 null and combined GSTM1/GSTT1 null phenotypes are strong risk factors for atherogenesis in the Serbian population. It must be emphasized however, that the statistical power to detect association may be limited due to the relatively small sample size of both atherosclerotic patients (200) and controls (182), leading to false positive results. Recruitment and survival bias cannot be ruled out either, in particular among controls who may develop atherosclerosis in the future (Guo et al., 2013). A study on a larger group of atherosclerotic patients, with and without diabetes mellitus should also be considered in order to avoid this confounding element.

In conclusion, coupled deletions of GSTM1 and GSTT1 genes may play a significant role in the etiopathogenesis of atherosclerosis and may represent a useful marker in the prediction of disease susceptibility in Serbs.

\section{Acknowledgments}

This study has been financed by the grant 175075 of the Ministry of Education, Science and Technological Development of Serbia.

\section{References}

Berhane K, Widersten M, Engström A, Kozarich JW and Mannervik B (1994) Detoxication of base propenals and other alpha, beta-unsaturated aldehyde products of radical reactions and lipid peroxidation by human glutathione transferases. Proc Natl Acad Sci U S A 91:1480-1484.

Chobanian AV, Bakris GL, Black HR, Cushman WC, Green LA, Izzo Jr JL, Jones DW, Materson BJ, Oparil S, Wright Jr JT, et al. (2003) Seventh report of the Joint National Committee on Prevention, Detection Evaluation and Treatment of High Blood Pressure. Hypertension 42:1206-1252.

Cora T, Tokac M, Acar H, Soylu A and Inan Z (2013) Glutathione S-transferase Ma and T1 genotypes and myocardial infraction. Mol Biol Rep 40:3263-3267.

Dalepiane VLN, Sivello DN, Paludo CA, Roisenberg I and Simon D (2007) Matrix metalloproteinase gene polymorphisms in patients with coronary artery disease. Genet Mol Biol 30:505-510.

Doney AS, Lee S, Leese GP Morris AD and Palmer CN (2005) Increased cardiovascular morbidity and mortality in Type 2 diabetes is associated with the glutathione S-transferase theta-null genotype, A Go-DARTS study. Circulation 111:2927-2934.

Dordevic V, Nikolic A, Ljujic M, Nestorovic A, Ristanovic M, Tulic C and Radojkovic D (2010) Combined effects of GSTM1 gene deletion, GSTT1 gene deletion and MTHFR C677T mutation in male infertility. Arch Biol Sci 62:525530 .

Douglas KT (1987) Mechanism of action of glutahtionedependent enzymes. Adv Enzymol Relat Areas Mol Biol 59:103-167.
Eaton DL and Bammler TK (1999) Concise review of the glutathione S-transferases and their significance to toxicology. Toxicol Sci 49:156-164.

Futterman LG and Lemberg L (1998) Fifty percent of patients with coronary artery disease do not have any of the conventional risk factors. Am J Crit Care 7:240-244.

Guo C, Hu F, Zhang S, Wang Y and Liu H (2013) Association between osteoprotegerin gene polymorphisms and cardiovascular disease in type 2 diabetic patients. Genet Mol Biol 36:177-182.

Hayes JD and McLellan LI (1999) Glutathione and glutathionedependent enzymes represent a co-ordinately regulated defence against oxidative stress. Free Radic Res 31:273-300.

Hayes JD and Strange RC (2000) Glutathion S-transferase polymorphisms and their biological consequences. Pharmacology 61:154-166.

Hiragi CO, Vilela ALM, Rocha DMS, de Oliveira SF, Hatagima A and Klautau-Guimarães NM (2011) Superoxide dismutase, catalase, glutathione peroxidase and glutathione Stransferases M1 and T1 gene polymorphisms in three Brazilian population groups. Genet Mol Biol 34:11-18.

Katakami K, Sakamoto K, Kaneto H, Matsuhisa M, Shimizu I, Ishibashi F, Osonoi T, Kashiwagi A, Kawamori R, Hori M, et al. (2009) Combined effect of oxidative stress-related gene polymorphisms on atherosclerosis. Biochem Biophys Res Commun 379:861-865.

Lima CSP, Neri IA, Lourenco GJ, Faria ICJ, Ribeiro JD and Bertuzzo CS (2010) Glutathione S-transferase mu 1(GSTM1) and theta 1 (GSTT1) genetic polymorphisms and atopic asthma in children from Southeastern Brazil. Genet Mol Biol 33:438-441.

Mir R, Bhat MA, Javaid J, Shah N, Kumar P, Sharma E, Jhu C, Basak S, Amle D, Ray PC, et al. (2016) Glutathione S-transferase M1 and T1 (rs 4025935 and rs71748309) null genotypes are associated with increased susceptibility to coronary artery disease in Indian populations. Acta Cardiol 71:678-684.

Nasr AS, Sami RM, Ibrahim NY and Darwish DO (2015) Glutathione S-transferase (GSTP1, GSTM1 and GSTT1) gene polymorphisms in Egyptians with acute myeloid leukemia. Indian J Cancer 52:490-495.

Nørskov MS, Frikke-Schmidt R, Loft S, Sillensen H, Grande P, Nordestgaard B and Tybjaerg-Hansen A (2011) Copy number variation in glutathion S-transferases $\mathrm{Ma}$ and $\mathrm{T} 1$ and ischemic vascular disease. Circ Cardiovasc Genet 4:418428.

Olsen RK, Cornelius N and Gregersen N (2013) Genetic and cellular modifiers of oxidative stress: What can we learn from fatty acid oxidation defects? Mol Genet Metab 10:S31-S39.

Polimanti R, Carboni C, Baesso I, Piacentini S, Iorio A, De Stefano GF and Fuciarelli M (2013) Genetic variability of glutathione S-transferase enzymes in human populations: functional inter-ethnic differences in detoxification systems. Gene 512:102-107.

Ramprasath T, Senthil Murugan P, Prabakaran AD, Gomathi P, Rathinavel A and Selvam GS (2011) Potential risk modifications of GSTT1, GSTM1 and GSTP1 (glutathione-Stransferases) variants and their association to CAD in patients with type-2 diabetes. Biochem Biophys Res Commun 407:49-53. 
Santl Letonja M, Letonja M, Ikolajevic-Starcevic JN and Petrovic D (2012) Association of manganese superoxide dismutase and glutathione S-transferases genotypes with carotid atherosclerosis in patients with diabetes mellitus type 2 . Int Angiol 31:33-41.

Sharma R, Ansari GAS and Awasthi YC (2006) Physiological substrates of Glutathione S-Transferases. In: Awasthi YC (ed) Toxicology of Glutation Transferases. CRC Press, New York, pp 179-203.

Sharma N, Singh A, Singh N, Behera D and Sharma S (2015) Genetic polymorphisms in GSTM1, GSTT1 cand GSTP1 genes and risk of lung cancer in a North Indian population. Cancer Epidemiol 39:947-955.

Souza CL, Barbosa CG, Moura Neto JP, Barreto JH, Reis MG and Gonçalves MS (2008) Polymorphisms in the glutathione S-transferase theta and mu genes and susceptibility to myeloid leukemia in Brazilian patients. Genet Mol Biol 31:39-41.

Suvakov S, Damjanovic T, Stefanovic A, Pekmezovic T, SavicRadojevic A, Pljesa-Ercegovac M, Matic M, Djukic T, Coric V, Jakovljevic J, et al. (2013) Glutathione S-transferase A1, M1, P1 and T1 null or low-activity genotypes are associated with enhanced oxidative damage among haemodialysis patients. Nephrol Dial Transplant 28:202-212.
Türkanoglu A, Can Demirdögen B, Demirkaya S, Bek S and Adali O (2010) Association analysis of GSTT1, GSTM1 genotype polymorphisms and serum total GST activity with ischemic stroke risk. Neurol Sci 31:727-734.

Voso MT, D'Alo F, Putzulu R, Mele L, Scardocci A, Chiusolo P, Latagliata R, Lo-Coco F, Rutella S, Pagano L, et al. (2002) Negative prognostic value of glutathion S-transferase (GSTM1 and GSTT1) deletions in adult acute myeloid leukemia. Blood 100:2703-2707.

Wang J, Zou L, Huang S, Lu F, Lang X, Han L, Song Z and Xu Z (2010) Genetic polymorphisms of glutathion S-transferase genes GSTM1, GSTT1 and risk of coronary heart disease. Mutagenesis. 25:365-369.

Yang H, Yang S, Liu J, Shao F, Wang H and Wang Y (2015) The association of GSTM1 deletion polymorphism with lung cancer risk in a Chinese population: Evidence from an updated meta-analysis. Sci Rep 5:9392.

Yeh HL, Kuo LT, Sung FC, Chiang CW and Yeh CC (2013) GSTM1, GSTT1, GSTP1 and GSTA1 genetic variants are not associated with coronary artery disease in Taiwan. Gene 523:64-69.

Associate Editor: Regina Mingroni Netto

License information: This is an open-access article distributed under the terms of the Creative Commons Attribution License (type CC-BY), which permits unrestricted use, distribution and reproduction in any medium, provided the original article is properly cited. 